\title{
Comparison of an empirical S-wave velocity model and a calculated stress-strain model for a rock mass disturbed by mining
}

\author{
Krzysztof Krawiec ${ }^{1 *}$, Rafat Czarny ${ }^{1}$ \\ ${ }^{1}$ Mineral and Energy Economy Research Institute, Polish Academy of Sciences, 31-261 Krakow, \\ Poland
}

\begin{abstract}
In the article a comparison analysis is presented between a numerical model of the stress and deformation state in a rock mass and an $\mathrm{S}$-wave velocity model obtained as a result of in situ measurement. The research was conducted using data from the Jastrzębie and Moszczenica coal mines. The part of the rock mass examined was strongly disturbed by multi-seam exploitation of coal. To obtain the S-wave velocity model 6 hours of ambient seismic noise data were recorded using 11 seismometers. The propagation of the Rayleigh surface wave between the seismometers was reconstructed utilising the seismic interferometry and the cross correlation technique. Estimation of a two dimensional model of the Swave velocity field was performed on the basis of dispersion curves of the Rayleigh wave phase velocity. The stress and deformation field were calculated assuming a plane state of stress with the use of the elastic-plastic Coulomb-Mohr strength criterion. Images of the vertical stress, horizontal stress, vertical strain and horizontal strain as well as the subsidence profile on the model surface were obtained as a result of the calculation. Analysis of the results shows correlation between the field of S-wave velocity and the modelled field of stress and strain.
\end{abstract}

\section{Introduction}

Information about the stress and deformation processes developing in a rock mass disturbed by underground mining is essential in terms of the terrain surface subsidence and its effect on structures and the environment [1-3]. Moreover, strong seismicity may be induced in zones with a high stress gradient $[4,5]$.

One of the parameters that describe the stress and deformation changes in the rock mass is the velocity of seismic waves [6]. In mines this parameter has mainly been determined by seismic profiling [7, 8] or active and passive seismic tomography [9-11]. Recently, seismic interferometry has also been used for imaging $[12,13]$ and monitoring of the rock mass influenced by mining $[14,15]$. This cost-effective tool can turn seismic noise into a useful signal produced by a so-called "virtual seismic source" [16].

\footnotetext{
*Corresponding author: k.krawiec@ meeri.pl
} 
A wide range of numerical modelling codes has been used to investigate the stress and deformation changes induced by underground coal mining [17]. Among these the FLAC code is a well-known computer code for such analysis of rock engineering problems using the FVM/FDM approach with a vertex scheme of triangular and/or quadrilateral grids[18, 19]. Application of FLAC codes in the modelling of the exploitation of multiple coal seams was widely described by Kwaśniewski and Wang [20], Kook et al. [21], Han et al. [22], Pilecki [23], Wesołowski [24], Zhang et al. [25], Sui et al. [26], Zhu et al. [27].

In this paper, the measured S-wave velocity field and numerically modelled stressdeformation field of a rock mass disturbed by the exploitation of multiple coal seams are compared. In the initial part of the paper, we show the location of the research area and we present brief information about the geological and mining conditions in the Jastrzębie and Moszczenica coal mines in Poland. Then, the methodology of the S-wave velocity model using seismic interferometry with ambient seismic noise is explained. Next, we describe the methodology of numerical calculations of stress and deformation fields.

Finally, we analyse the characteristic features of the empirical seismic velocity model comparing it to the calculated stress and deformation model. The conclusions formulated correspond to the relationship between changes in S-wave velocity and the stress and deformation processes induced by mining.

\section{Geological and mining conditions}

The research area is located at Jastrzębie and Moszczenica mines near to the town of Jastrzębie-Zdrój in southern Poland (Fig. 1a). The locations of profiles M1-M1' for numerical calculations and profile P1-P1' for the empirical S-wave velocity model, together with information about the geological and mining conditions, are shown in Figure $1 \mathrm{~b}$. Profiles P1-P1' and M1-M1' were located across a pillar used as a protective boundary between coal mines (Fig. 1b, red dashed line). Underground mining of coal has taken place in the research area since the 1960's (Fig. 1b, white line).

(a)

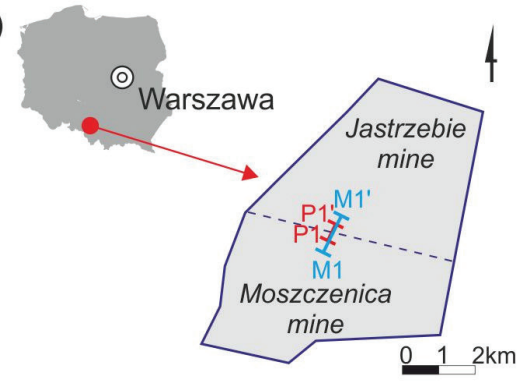

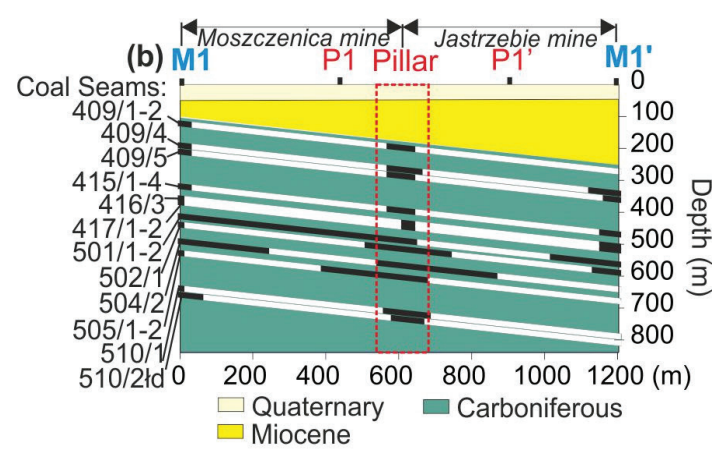

Fig. 1. Location of numerical modelling profile M1-M1' and S-wave velocity profile P1-P1' at Jastrzębie and Moszczenica mines; (b) Geological cross-section for M1-M1' and P1-P1' profiles. The white and black lines indicate exploited and unexploited coal seams, respectively. The red dashed line indicates the pillar between the Jastrzębie and Moszczenica mines (based on [30]).

The Carboniferous formation is composed of clastic rocks such as sandstones, mudstones and hard coal seams. This formation dips from south to north at an average inclination of 7 degrees. Miocene and Quaternary sediments occur above these seams from a depth of about $170 \mathrm{~m}$ to the ground surface. These sediments are composed of gravels, sands, clay and sandstones. 


\section{Methodology}

\subsection{S-wave velocity model}

An S-wave velocity model was calculated on the basis of seismic interferometry with the use of ambient seismic noise. The array contained 11 broadband seismometer stations Guralp CMG-6td. The stations were deployed on the ground surface along profile P1-P1' (Fig. 2a). The time of 6 hours of ambient seismic noise data with $100 \mathrm{~Hz}$ frequency sampling were recorded and processed according to the methodology presented by Bensen et al. [28]. The main processing procedures contained: detrend, bandpass filtering $(0.5-10$ $\mathrm{Hz}$ ), 1-bit normalisation, spectral whitening and cross-correlation of all available combinations of station pairs. The example of cross-correlation functions (CCFs) for station $\mathrm{G} 1$ as a virtual seismic source is shown in figure $2 \mathrm{~b}$.

Because the main energy of seismic noise comes from the northerly direction from traffic on active roads, working mine surface machines etc., the only positive part of the $\mathrm{CCFs}$ shows a Rayleigh surface wave (Fig. 2b). Based on various combinations of CCFs, 14 dispersion curves were identified along profile P1-P1' (Fig. 2c, d). Each dispersion curve was inverted to a $1 \mathrm{D} \mathrm{S}$-wave velocity model by using the gradient algorithm of Xia et al. [29]. The depths of the main geological formation (Fig 1b) were used in the inversion procedure. Finally, the 2D S-wave velocity model along profile P1-P1' was interpolated and correlated with the geology and mining information (Fig. 3).
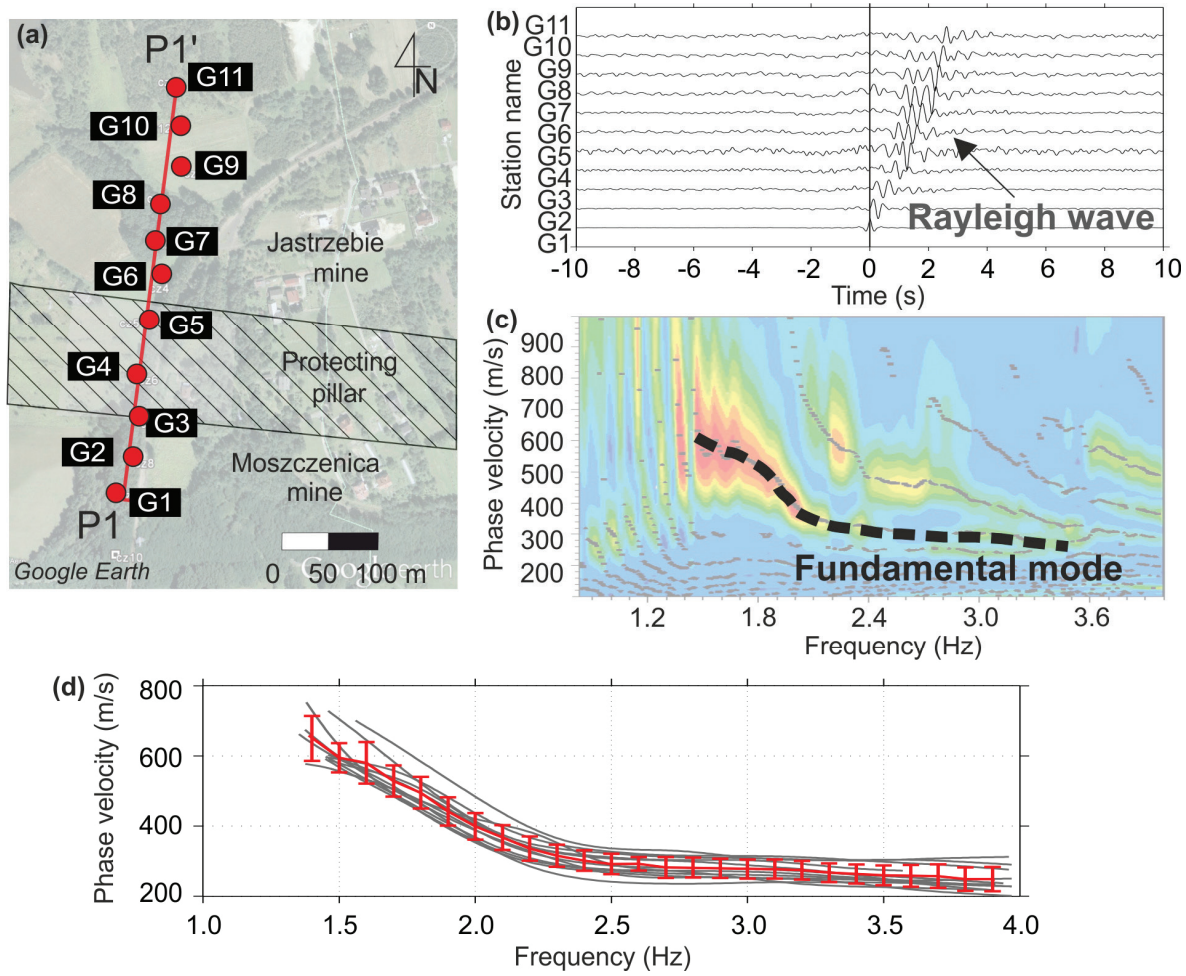

Fig. 2. (a) Location of stations G1-G11 along the profile P1-P1'; (b) an example of CCFs for a virtual source in station G1; (c) an example of the identification of the Rayleigh wave dispersion curve; (d) all dispersion curves computed along profile P1-P1' (based on [30]). 


\subsection{Numerical modelling}

\subsubsection{Physical model}

The physical model was constructed on the basis of the geological cross-section along the M1-M1' profile (Fig. 1b). The model was $1200 \mathrm{~m}$ long, $840 \mathrm{~m}$ deep and consisted of 29 geological layers. The 12 coal seams were included in the model with the exploited working faces marked.

The information about the material properties was established on the basis of analogy with data from the coal mine and expert opinion. Averaged values of the material properties for each layer were assumed when carrying out the calculations (Tab. 1).

Table 1. Material properties.

\begin{tabular}{|c|c|c|c|c|}
\hline & Miocene & Sandstone & Shale & Hard coal \\
\hline Young's Modulus [GPa] & 1.5 & 19.3 & 11.1 & 0.75 \\
\hline Poisson ratio [-] & 0.25 & 0.38 & 0.29 & 0.25 \\
\hline Bulk density [kg/m $\left.{ }^{3}\right]$ & 2000 & 2700 & 2700 & 1922 \\
\hline Cohesion [MPa] & 0.3 & 27.2 & 38.4 & 0.15 \\
\hline Tension [MPa] & 0 & 1.17 & 14.4 & 0 \\
\hline Angle of internal friction [deg] & 38 & 27.8 & 14.4 & 20 \\
\hline
\end{tabular}

\subsubsection{Calculation model}

Numerical calculations were conducted assuming a plane state of stress with the use of the elastic-plastic Coulomb-Mohr strength criterion. A two dimensional state of stress was modelled in a quasi-spatial nature. The two horizontal components of the main stress have equal values. The values of the primary vertical and horizontal stress components were changeable in the range of model depth [23]. On the laterals and the bottom edges of the model, displacement boundary conditions were established. The horizontal displacement was constrained along the vertical boundaries of the grid and no displacements were allowed at the base of the model. Motion of the nodes on the model surface was permitted in both directions. The dimensions of the grid elements approached the size of $2 \times 2 \mathrm{~m}$.

The calculations consist of 24 stages. In the first stage the model was calculated to obtain the equilibrium state assuming the gravitational distribution of primary stress. In subsequent stages, parts of the coal seams were excavated chronologically. After the excavation of one part of the coal seam, calculations were allowed until the vertical displacements in the roof reached the value of $95 \%$ of the height of the seam. The values of the properties of backfill material were equal to $75 \%$ of the values assumed for hard coal layers. In the next part, the model was calculated to obtain the equilibrium state of secondary stress. Images of vertical stress, horizontal stress, vertical strain and horizontal strain as well as the subsidence profile on the ground surface were obtained as a result of this calculation. The calibration of the numerical model was undertaken using a comparison of the subsidence curve along the M1-M1' profile with geodetic measurement data. The subsidence profile thus calculated approximately coincided with geodetic measurement data (Fig. 3). In the middle part of the curves one can see the location of the pillar on a profile with much smaller values of subsidence. 


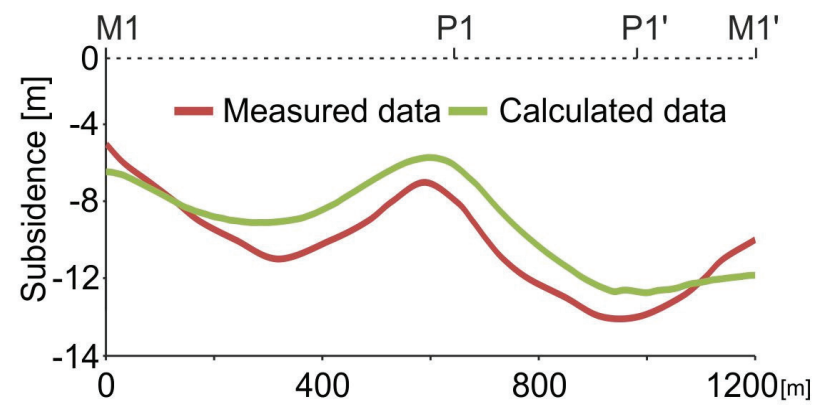

Fig. 3. The comparison of the subsidence curve for measured and calculated data.

\section{Results and analysis}

The S-wave velocity cross-section along the P1-P1' profile is presented in Figure 4. The largest velocity increase is observed in the top of the Carboniferous formation. Along the pillar (Fig. 4, between red dashed lines) and within the Quaternary and Miocene formations, the velocity decreases by about $100 \mathrm{~m} / \mathrm{s}$ in comparison with the exploited area.

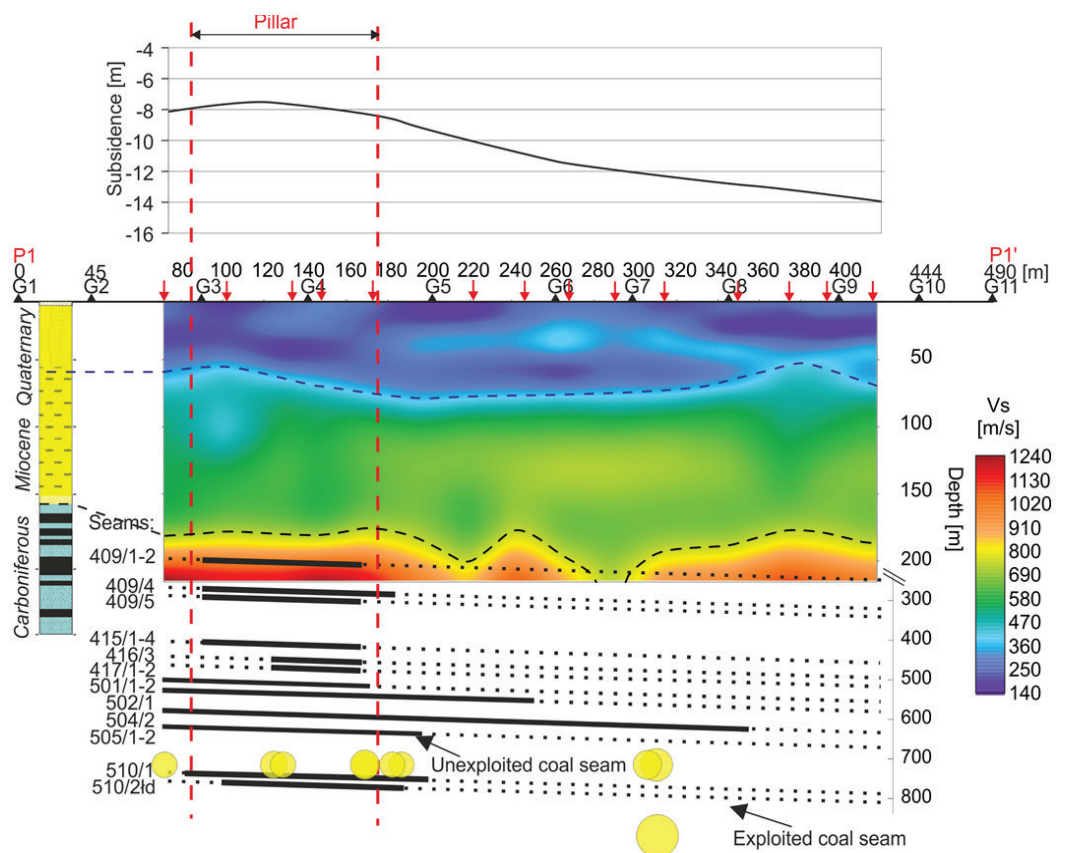

Fig. 4. An S-wave velocity model along the P1-P1' profile; the red arrows above the cross-section indicate locations of $1 \mathrm{D}$ S-wave profiles; the yellow dots indicate seismic events greater than $10^{5} \mathrm{~J}$ occurring during the most recent mining activity in seams 510/1 and 510/2 (based on [30]).

This is caused by the deformation process of the rock mass due to exploitation. At the top of the Carboniferous layer the largest velocity with an average value of about $1200 \mathrm{~m} / \mathrm{s}$ is seen in the pillar. In the same formation, but in the exploited area, the velocity shows a significant decrease with an average value of about $970 \mathrm{~m} / \mathrm{s}$. Generally the S-wave velocity field in the exploited area is much more complicated than within the pillar. The velocity increase in the pillar at the top of the Carboniferous layer can be caused by the 
concentration of stress and/or local geology. Moreover, a strong stress gradient around the pillar can induce seismic events. The irregularly-shaped border of the Carboniferous layer above the exploited area is the reason for mining multiple-seams of coal. The curve of subsidence correlates with the velocity of the Carboniferous formation.

The vertical stress field after the exploitation of the last coal seam 510/2łd is presented in Figure 5a. The vertical stress reaches the highest values of the order of $-90 \mathrm{MPa}$ (minus denotes compression) in the area of the safety pillar with coal remnants localised at a depth of about $440 \mathrm{~m}$. The values are nine times greater than the primary stress values in that area. Concentration of compressive stress appears in almost the entire pillar and ranges from the floor of the Miocene formations to the bottom of the model. Beyond the pillar strong concentrations of compressive vertical stress are observed near the edge of the mined areas. The destressed zone appears in almost the entire section of the modelled rock mass in the vicinity of the exploited areas. The values of vertical stress are several times smaller than the values of the primary vertical stress. Destressed areas range from the surface to the bottom of the model at a depth of $840 \mathrm{~m}$.

A comparison of the vertical stress field with the S-wave velocity field is presented in Figure 5c. The S-wave velocity increases in the area of higher values of compressive vertical stress in the pillar, which lies at a depth from 160 to $200 \mathrm{~m}$.

The horizontal stress field, which is mostly compressive, is presented in Figure 5b. Strong concentration of horizontal stress appears mainly in sandstone layers and has much larger values than the primary horizontal stress. The maximum value of stress is about -186 MPa and appears in the roof layer of the 415/1-4 seam in the area of the pillar at a depth of $350 \mathrm{~m}$. Zones of tensile horizontal stress which values reaches about $9 \mathrm{MPa}$ are also observed in the model. These zones are located in the floor layers of the 409/5, 417/1-2 and 505/1-2 seams within the pillar. In addition, directly above the roofs of the exploited seams one can see a significant decrease in compressive stress values which sometimes change to tensile stress.

A comparison of the horizontal stress field with the S-wave velocity field is presented in Figure 5d. The highest values of compressive horizontal stress are concentrated within the pillar at a depth from 160 to $200 \mathrm{~m}$. In the pillar area, where the values of stress are greater, the $\mathrm{S}$-wave velocity increases.

The vertical strain field is presented in Figure 6a. The sign before the values of strain denotes the direction. The areas of highest values of vertical strain are localised in the zones of goaf. In addition, the fields of high values of strain appear within the pillar at a depth of from 60 to $180 \mathrm{~m}$.

A comparison of the vertical strain field with the S-wave velocity field is presented in Figure $6 \mathrm{c}$. The area of high values of strain within the pillar at a depth from 60 to $160 \mathrm{~m}$ is partially correlated with decreases in the S-wave velocity.

The horizontal strain field is presented in Figure $6 \mathrm{~b}$. The areas of the highest values of horizontal strain are localised within the pillar from surface of the model to a depth of 220 $\mathrm{m}$ below the ground surface. In addition, the fields of high values of strain appear near the sidewalls.

A comparison of the horizontal strain field with S-wave velocity field is presented in Figure $6 \mathrm{~d}$. The strain decrease at a depth of from 60 to $160 \mathrm{~m}$ within the pillar corresponds to a lesser increase in the S-wave velocity.

Based on the obtained results it can be summarised that in the areas with strong concentrations of stress and strain the S-wave velocity fluctuates. It could be connected with the changes in elastic properties of the rock mass. 


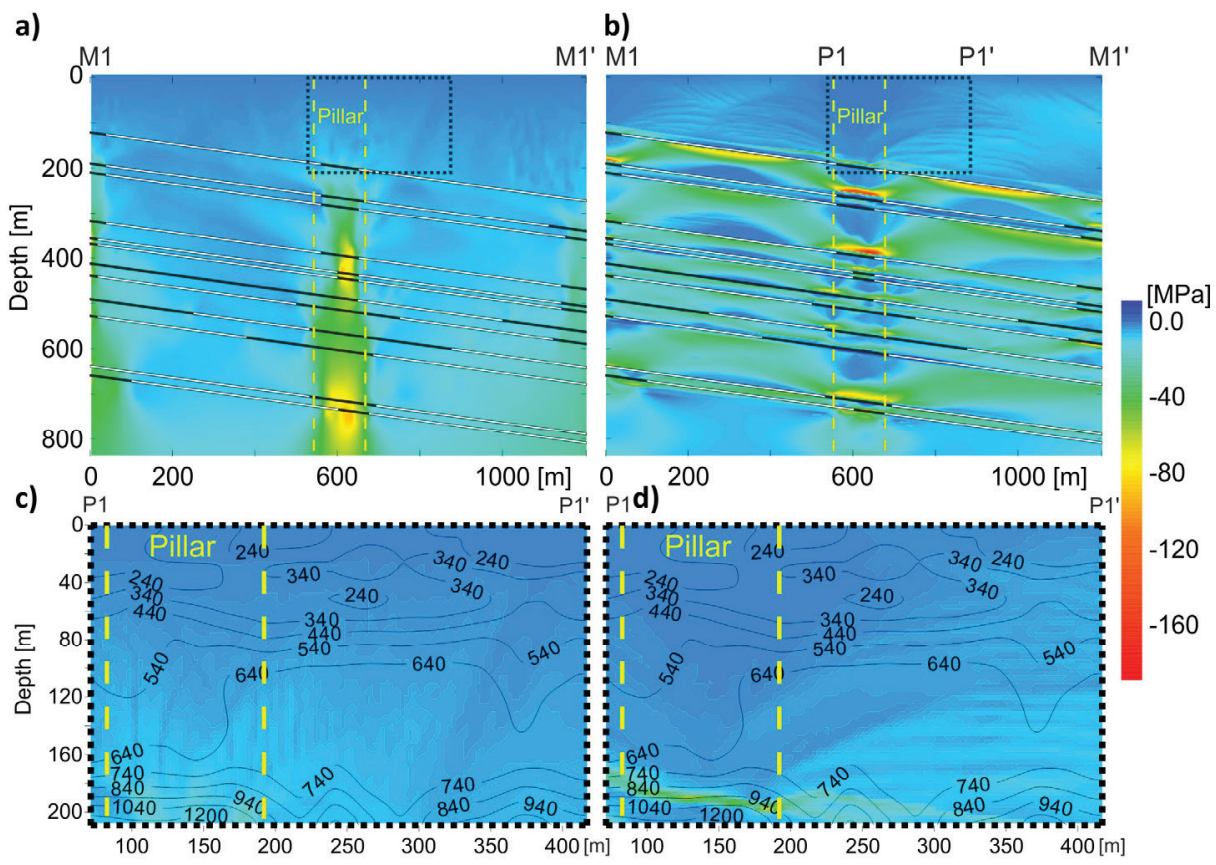

Fig. 5. (a) Vertical stress field, (b) Horizontal stress field (black dashed line indicates the range of the $\mathrm{S}$-wave velocity model) (c) Comparison of the vertical stress component and S-wave velocity (black isolines) (d) Comparison of the horizontal stress component and the S-wave velocity (black isolines).

a)

b)

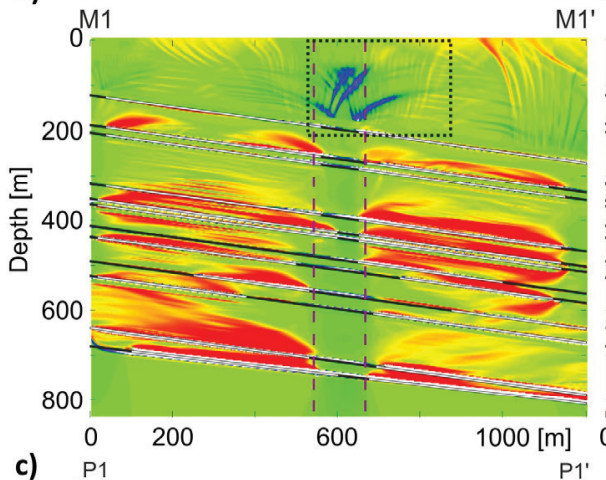
M1' M1
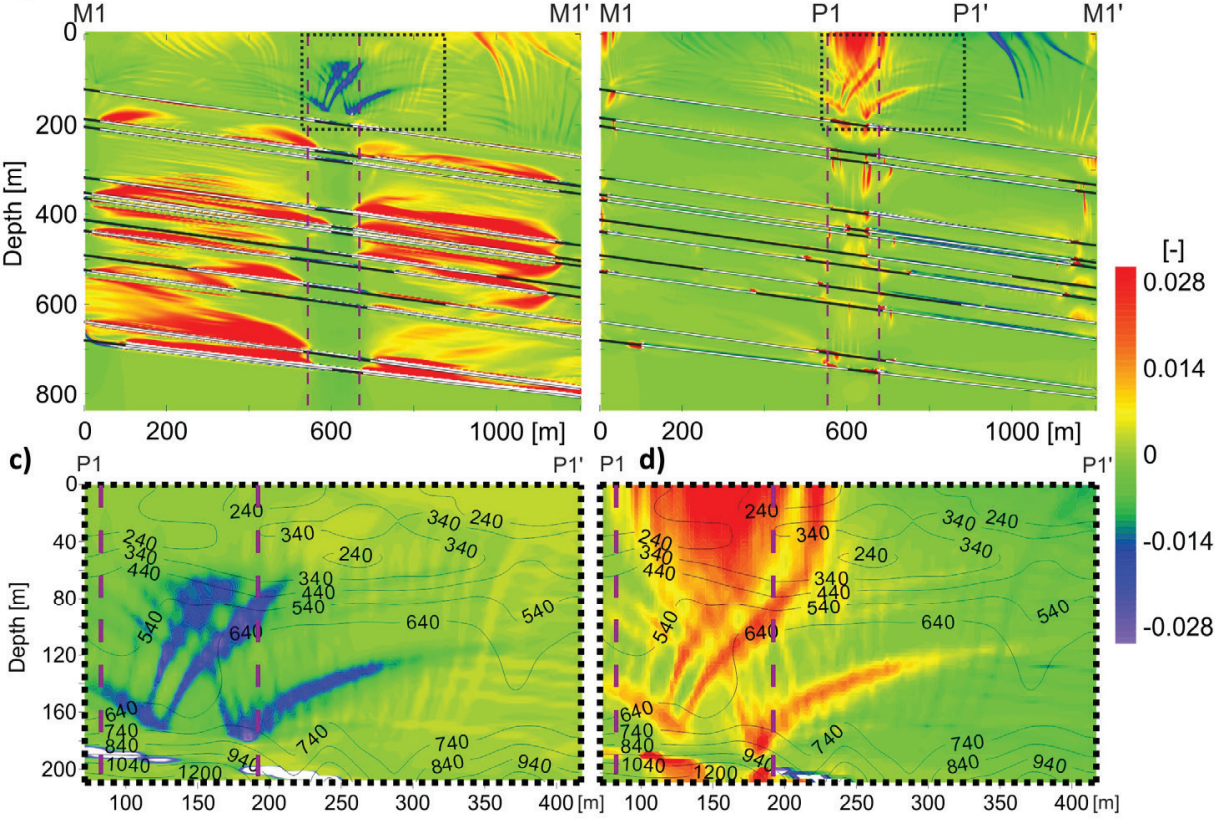

Fig. 6. (a) Vertical strain field, (b) Horizontal strain field (black dashed line indicates the range of Swave velocity model) (c) Comparison of the vertical strain component and S-wave velocity (black isolines) (d) Comparison of the horizontal strain component and S-wave velocity (black isolines). 


\section{Conclusions}

This article presents the results of a comparison between the numerical calculations of the stress and deformation state in a rock mass disturbed by multi-seam coal exploitation and an empirical model of the S-wave velocity obtained on the basis of the seismic interferometry method. Based on the outcomes of the research conducted, the following conclusions were drawn:

1. In the areas of increase of vertical and horizontal stress within the pillar, which consisted of coal seam remnants, the velocity of the $\mathrm{S}$-wave is greater in comparison with the destressed zones of the rock mass.

2. In the areas of high values of vertical and horizontal strain within the top part of the pillar, the S-wave velocity decreases.

3. The limited range of the S-wave velocity model does not allow comprehensive imaging of the disturbed rock mass to be carried out.

4. The preparation of 3D models: numerical and empirical S-wave velocity would allow one to obtain more detailed results.

5. Presented methodology can be useful to study subsidence process and monitoring of bent layers.

This article was prepared as a result of the LOFRES Project No PBS1/A2/13/2013 performed within the 1st call of the Applied Research Programme co-financed by the National Centre for Research and Development in Poland. We thank the editor and two anonymous reviewers for valuable comments and discussions.

\section{References}

1. E. Popiołek, Z. Pilecki, Evaluation of development possibilities of mining areas threatened with deformations using geophysical methods (MEERI PAS, Kraków, 2005)

2. H. Marcak, Z. Pilecki, Some geophysical and geomechanical remarks on recognition of sinkhole processes in post-mining areas, Proc. of the 12th European Meeting of Environmental and Engineering Geophysics, Helsinki, Finland, 1-5 (2006)

3. Z. Pilecki, The role of geophysical methods in the estimation of sinkhole threat in the post-mining areas of shallow exploitation in the Upper Silesian Coal Basin, Poland Gospad. Surowcami. Min. 24(3/1), 27-40 (2008)

4. S. Gibowicz, A. Kijko, An Introduction to Mining Seismology (Academic Press, New York, 1994)

5. A. J. Mendecki, Seismic monitoring in mines (Chapman and Hal, London, 1997)

6. A. Nur, J. Geophys. Res. 76(8), 2022-2034 (1971) doi:10.1029/JB076i008p02022

7. Z. Szreder, Z. Pilecki, J. Kłosiński, Comparison of Profiling Results of Attenuation and Velocity of Refracted P-wave in Coal-seam, Proc. of the 14th European Meeting of Environmental and Engineering Geophysics, Kraków, Poland (2008)

8. J. Ślizowski, Z. Pilecki, K. Urbańczyk, E. Pilecka, L. Lankof, R. Czarny, Adv. High Energy Phys., 1-12 (2013) doi :10.1155/2013/461764

9. N. Hosseini, K. Oraee, K. Shahriar, K. Goshtasbi, J. Cent. South Univ. 19(8), 22972306 (2012) doi :10.1007/s11771-012-1275-Z

10. Z. Pilecki, M. Laskowski, A. Hryciuk, J. Wróbel, E. Koziarz, E. Pilecka, R. Czarny, K. Krawiec, Identification of gaso-geodynamic zones in the structure of copper ore deposits using geophysical methods, CIM Journal 5(3), 194-202 (2014) 
11. A. Cao, L. Dou, W. Cai, S. Gong, S. Liu, G. Jing, Int. J. Rock Mech. Min. Sci. 78, 1-9 (2015) doi: 10.1016/j.ijrmms.2015.05.001

12. G. Olivier, F. Brenguier, M. Campillo, R. Lynch, P. Roux, J. Geophys. Res. 80(3), KS11-KS25 (2015a) doi : 10.1190/geo2014-0299.1

13. G. Olivier, D. Hollis, F. Brenguier, A. Mordret, T. Lecocq, Proc. of the 79th EAGE Conference and Exhibition 2017, Paris, France (2017) doi: 10.3997/22144609.201700961

14. G. Olivier, F. Brenguier, M. Campillo, P. Roux, N. M. Shapiro, R. Lynch, Geophys. Res. Lett. 42, 1-9 (2015b) doi: 10.1002/2015GL065975

15. R. Czarny, H. Marcak, N. Nakata, Z. Pilecki, Z. Isakow, Pure Appl. Geophys. 173(6), 1907-1916, (2016) doi :10.1007/s00024-015-1234-3

16. A. Curtis, P. Gerstoft, H. Sato, R. Snieder, K. Wapenaar, The Leading Edge 25(9), 1082-1092 (2006) doi : 10.1190/1.2349814

17. B.H.G. Brady, E.T. Brown, Rock mechanics: for underground mining (Chapman \& Hall, London, 1993)

18. M. A. Coultard, Geotechnical and Geological Engineering 17(3-4), 373-385 (1999) doi : 10.1023/A:1008951216602

19. L. Jing, J. A. Hudson, Int. J. Rock Mech. Min. 39(4), 409-427 (2002) doi : 10.1016/S1365-1609(02)00065-5

20. M. Kwaśniewski, J. Wang, Numerical analysis of mining-induced deformations of the strata, Proc. of The School of Underground Mining '96, Kraków, Poland, 153-187 (in Polish) (1996)

21. J. Kook, C. Scior, P. Fischer, M. Hegemann, Subsidence predictionfor multiple seam extraction under consideration of time effects by the use of geomechanical numerical models, Proc. of the 27th International Conference on Ground Control in Mining, WV, USA, 143-147 (2008)

22. J. Han, H. W. Zhang, P. Zhang, J. Zhang, M. Li, Overmining in Kailuan, China mining area, Proc. of the 28th International Conference on Ground Control in Mining, WV, USA, 305-311 (2009)

23. Z. Pilecki, Modelowanie numeryczne pola naprężenia $w$ górotworze naruszonym wielopokładowa eksploatacja węgla kamiennego $w$ warunkach silnego zagrożenia sejsmicznego, Zeszyty Naukowe - Bulletin of the Mineral and Energy Economy Research Institute of the Polish Academy of Sciences 80, 93-102 (in Polish) (2011)

24. M. Wesołowski, Modelowanie numeryczne wptywu zaszłości eksploatacyjnych na deformacje terenu górniczego na przykładzie kopalni „Chwatowice”, Przegląd Górniczy 69(6), 27-35 (in Polish) (2013)

25. M. Zhang, H. Shimada, T. Sasaoka, K. Matsui, L. Dou, Environ. Earth Sci. 72(3), 629643 (2014) doi :10.1007/s12665-013-2985-8

26. W. Sui, Y. Hang, L. Ma, Z. Wu, Y. Zhou, G. Long, L. Wei, B. Eng. Geol. Environ. 74(3), 1019-1035 (2015) doi :10.1007/s10064-014-0674-9

27. G.A. Zhu, L.M. Dou, Z.L. Li, W. Cai, Y. Kong; J. Li, Arab. J. Geosci. 9, 365 (2016) doi :10.1007/s12517-016-2356-3

28. G.D. Bensen, M.H. Ritzwoller, M.P. Barmin, A.L. Levshin, F. Lin, M.P. Moschetti, N.M. Shapiro, Y. Yang, Geophys. J. Int. 169(3), 1239-1260 (2007) doi: 10.1111/j.1365-246X.2007.03374.X

29. J. Xia, R.D. Miller, C.B. Park, Geophysics 64(3), 691-700 (1999) doi: $10.1190 / 1.1444578$ 
30. Z. Isakow, Z. Pilecki, A. Kubańska, System LOFRES sejsmiki pasywnej z wykorzystaniem szumu sejsmicznego (Instytut Technik Innowacyjnych EMAG, Katowice, in Polish, 2015) 